\title{
Advocating mixed-methods approaches in health research
}

MacKenzie Bryers $H^{1-2}$, van Teijlingen E ${ }^{3-5}$, Pitchforth $E^{6}$

${ }^{1}$ Head of Midwifery, NHS Highland, Inverness, UK.

${ }^{2}$ Honorary Research Fellow, Centre for Rural Health, University of Aberdeen.

3 Professor, School of Health \& Social Care, Bournemouth University, Bournemouth, UK.

4 Visiting Professor, Manmohan Institute of Health Science, Tribhuvan University, Nepal.

5 Visiting Professor, Nobel College, Pokhara University, Kathmandu, Nepal.

${ }^{6}$ Research Leader, RAND Europe, Cambridge, UK.

Chief Editor

Dr. Brijesh Sathian

Technical Editor

Dr. Nishida Chandrasekharan

Formatting Editor

Dr. Abhilash E S
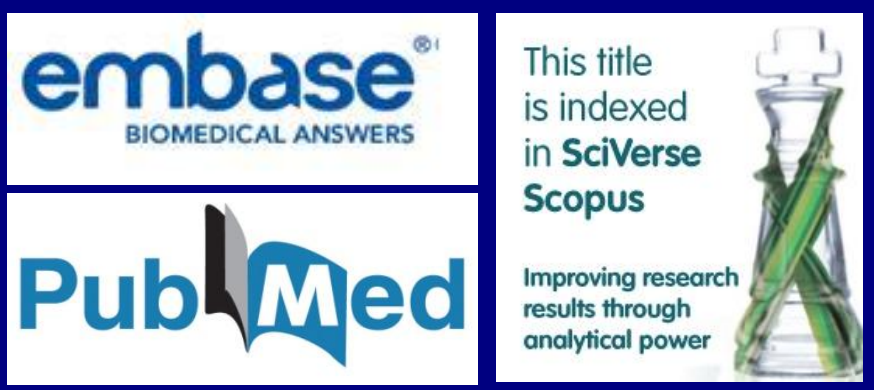

\section{Review Article}

\section{Corresponding Author}

Dr. Helen Bryers, NHS Highland, Assynt House, Beechwood Park, Inverness IV2 3BW, Scotland, UK

E-mail: helen.bryers@nhs.net

\section{Abstract}

This methods paper provides researchers in Nepal with a broad overview of the practical and philosophical aspects of mixed-methods research. The three authors have a wideranging expertise in planning and conducting mixedmethods studies. The paper outlines the different paradigms or philosophies underlying quantitative and qualitative methods and some of the on-going debates about mixed-methods. The paper further highlights a number of practical issues, such as (a) the particular mix and order of quantitative and qualitative methods; (b) the way of integrating methods from different philosophical stance; and (c) how to synthesise mixed-methods findings.

Keywords: Quantitative research; Qualitative research; Mixed Methods Research

\section{Background}

With the growing number of health studies in Nepal using more than one research methods, this paper offers insight into the 'pragmatic paradigm' or, 'mixed-methods approach' as it is more commonly known. In mixed-methods studies a number of quantitative and qualitative methods can be combined within one research project. Mixedmethods may be used at any stage of research from the beginning including defining the research question to the end stage to help determine the generalisability of the findings ${ }^{1}$. The approach is not new in high-income countries $^{2-4}$, where it has a growing support in the health services and health care research field ${ }^{1,5}$. This paper provides an overview of the development and use of mixedmethods research as a paradigmatic framework and draw lessons for the use of mixed-methods in health services and public health research. 


\section{Advocating mixed-methods approaches}

\section{Methodology \& Methods in healthcare research}

The terms methodology and methods are sometimes used interchangeably, but each has a distinct meaning. Methodology is the theory, sometimes referred to as the paradigm, behind the technical tools or methods which are used to gather and analyse information ${ }^{6}$. This distinction between methodology and methods is important in our understanding of mixed-methods.

Until recently, two distinct research methodologies were recognised. The positivist paradigm is based on objectivism, rational and scientific assumptions that nature is an ordered and complex phenomenon best understood by reducing it to basic quantitative parts ${ }^{7}$, and epidemiology fits well into this paradigm. An example of this is the quantitative method of the collection of data on the weight of newborn babies, or the number of adults who have bowel cancer Kathmandu Valley in 2015.

Quantitative research begins with predetermined, instrument-based questions, designed to test a priori hypotheses. Whilst qualitative methods typically involve a naturalistic or holistic collection of data through interviews or observation ${ }^{8}$.

Out of dissatisfaction with this established approach, a second methodology called the constructivist or naturalistic paradigm emerged ${ }^{6}$. This paradigm is based on social constructions and relativism and contends that reality is shaped by the individual and the culture rather than being absolute ${ }^{9}$. The example here would be the researcher might want to find out not only the baby's weight but try through a qualitative approach to understand how and why this was affected by behavioural, social or cultural factors.

From the 'incompatibility' of both these methodologies came an exploration of alternatives and gradually new paradigms, based on post-modernism and a 'compatibility' emerged $^{10-13}$. The most prominent is pragmatism or mixedmethods. This creates a bridge between qualitative and quantitative research, and is rapidly becoming the dominant methodology in the twenty-first century ${ }^{7}$.

It is seen as 'a compatibility thesis', a more 'applied' philosophy, and one that considers the research question more important than the method: the so-called 'dictatorship of the question' ${ }^{\mathbf{1 4}}$. It embraces the idea of 'methodological pluralism' ${ }^{15}$, and it rejects the idea of having to make a forced choice between qualitative and quantitative methods and the use of metaphysical concepts such as 'truth' and 'reality'. Mertens reasons that the questions and approach come first, and the applied paradigm is a framework used to clarify the assumptions about ethics, knowledge and systematic enquiry ${ }^{\mathbf{1 6}}$. It is important to note that although widely adopted, pragmatism and the use of mixed-methods, has been criticised because of the perception that anything goes in the field ${ }^{17}$.

Interesting parallels appear when this is applied to the field of maternal and child health $(\mathrm{MCH})$. The use of mixedmethods brings together elements that may be transferable into $\mathrm{MCH}$ knowledge: being able to describe reality in its complex state: holistic, cultural, political, economic and cultural rather than reduced to absolutes ${ }^{16}$. This can support the way we manage the 'whole woman' or 'unique normality' and moves away from the simplistic elements of reduction, for instance, dividing labour into three stages. Overall, this fits well with the development of evidencebased care and a move away from the assumption that there is a straightforward relationship between cause and effect, especially with regards the physiology of birth ${ }^{9,18}$.

\section{Mixed-methods: how and why}

Mixed-methods approaches have become more popular over the past two decades, for two key reasons: First to address research questions that a single method is unable to do: quantitative verifies theory, or addresses the "how many' question while qualitative generates theory or addresses the 'why' question'. Mixed-methods combines both approaches, for example, answers the quantitative how many women use the contraceptive pill question while qualitative methods address the why questions: why do some women use the pill and others use other forms of contraceptives? Secondly, the use of mixed-methods provides stronger inference and offset the disadvantages of a single method; and the results of each can validate each other.

Mixed-methods refers to how the various combinations of research methods are used at different stages of a study ${ }^{19}$. These stages can be at the same time, or carried out in a linear fashion. Table 1 summarises how qualitative and quantitative methods can be used in combination. It is useful and important to distinguish between 'mixedmethods' and 'multi-methods' studies. Using mixedmethods requires the integration, mixing, or linkage between the methods and their analyses, not just that more than one method is being used within the same study. According to Cresswell and colleagues ${ }^{20}$ its key strength lies in combining both qualitative and quantitative research provides a better understanding of a research problem than either research approach on its own.

Table 1: Ways of combining methods

\begin{tabular}{|c|c|}
\hline Sequence of Methods & Example \\
\hline $\begin{array}{c}\text { Qualitative before } \\
\text { quantitative }\end{array}$ & $\begin{array}{l}\text { Use focus groups (qualitative) to } \\
\text { establish the questions and question } \\
\text { order for large-survey questionnaire } \\
\text { (quantitative). }\end{array}$ \\
\hline $\begin{array}{c}\text { Quantitative before } \\
\text { qualitative }\end{array}$ & $\begin{array}{l}\text { Study of patient records (quantitative) } \\
\text { to find a correlation between treatment } \\
\text { and alcohol use in women over } 30 \text { and } \\
\text { use interviews (qualitative) to find out } \\
\text { why. }\end{array}$ \\
\hline $\begin{array}{c}\text { Quantitative \& qualitative in } \\
\text { parallel }\end{array}$ & $\begin{array}{l}\text { Questionnaire study (quantitative) to } \\
\text { establish how many pregnant women } \\
\text { smoke and interview (qualitative) a sub- } \\
\text { sample of these women to find out } \\
\text { what would help to smoke less. }\end{array}$ \\
\hline
\end{tabular}


The important point of these different sequences is to use the methods best suited to answer the overall research question, i.e. back to the dictatorship of the question. ${ }^{21}$ As examples, Mumtaz and Salway used a large scale quantitative survey and detailed ethnography to examine patterns of women's mobility and their relationship with antenatal care provision in Pakistan ${ }^{22}$. Pitchforth and colleagues used a mixed-methods qualitative approach that involved ethnographic observations, questionnaires for demographic data collections and semi-structured interviews with staff and patients as part of a larger project examining access to emergency obstetric care in Bangladesh $^{23}$.

Mixed-methods studies are not necessarily limited to two methods, for example, Pitchforth et al. (2006) used a mixedmethods qualitative approach that involved: (a) ethnographic observations; (b) questionnaires for demographic data collections; and (c) semi-structured interviews with staff and patients as part of a larger project examining access to emergency obstetric care in Bangladesh $^{23}$. Mixed-methods would also appear to fit well with primary care research where the questions can often be more complex than in an acute care setting ${ }^{24}$.

There are several good reasons for conducting mixedmethods research: (1) triangulation; (2) complementarily; (3) development; (4) initiation; and (5) expansion. ${ }^{25-26}$ Triangulation is used when the researcher seeks corroboration between: (a) sources; (b) data collection methods; (c) researchers and disciplines; and (d) quantitative and qualitative data analyses ${ }^{27-28}$. Complementarily refers to using one method to elaborate, expand or clarify the results of another. We can also use one method to help develop another, for example, focus groups to establish the questions for a quantitative questionnaire. Initiation seeks the discovery of paradox and contradiction, or recasting questions or results from one method, using another; and expansion refers to extending the breadth and range of study by using more than one method at the same time.

\section{Strengths of mixed-methods}

By combining methods the researcher can gain insight into the problem from different perspectives and is able to answer broader and more complex health questions. Using more than one method through triangulation of results, can help corroborate or confirm the findings, or offer a how many answer at the same time as a why one ${ }^{29}$ For example, adding qualitative interviews to a quantitative questionnaire can answer questions (what is $\mathrm{x}$ ) which the statistics highlight (how many $x)^{30}$. When findings are corroborated, or support each other across different approaches, then there is more confidence in the conclusions. When the results conflict, the researcher then has more information available and can modify interpretation and conclusions ${ }^{\mathbf{2 9}}$.

This means that, in order to make best use of mixedmethods, the researcher must have a good understanding of the strengths and weaknesses of both qualitative and quantitative research ${ }^{31}$. The advantage of this is that the

\section{Advocating mixed-methods approaches}

researcher becomes open to a broad range of research methods and can seek to answer a wider range of research questions. The integration of different types of methods has become acceptable in health services research as the strength of combining data from quantitative and qualitative sources becomes more apparent ${ }^{6}$. Its strength lies in the reduced bias and increased validity that comes through different approaches to the subject, a thoroughness of approaching a subject from different angles. The results can be therefore more persuasive, as each method has its own strength neither quantitative nor qualitative methods is all encompassing, i.e. even its area of greatest strength each method can be enhanced by triangulation with other methods. When the results conflict, the researcher then has more information and can modify interpretation and conclusions ${ }^{29}$.

\section{Weaknesses of mixed-methods}

As with any method, there are weaknesses in a mixedmethods approach ${ }^{6}$. One key weakness of a mixed-methods approach is that one divides limited resources, especially time and money among different methods, or to do it well a mixed-methods approach is more expensive and time consuming than using a single method. This opportunity costs means running each methods to a lesser level or it requires more resources to both methods well. In addition, work can be divided between academic disciplines as diverse as epidemiology and public health. This can lead to qualitative, quantitative researchers working together; however these disciplines operate with a different underlying philosophy and this can pose challenges in the interpretation and analysis ${ }^{6}$.

As mentioned above one weakness of a mixed-methods approach is that it divides limited resources. Thus using mixed-methods may result in a lost opportunity to conduct one large quantitative study or one more detailed qualitative study examining interviewees in further detail or conducting a deeper exploration of the topic ${ }^{29}$. Conducting a questionnaire study in conjunction with face-to-face interviews in a sub-sample one may end up with a smaller sample in the questionnaire or a lower response rate in the questionnaire study as some of the funding is diverted to the qualitative part of the study.

A further challenge of mixed-methods limiting its application is in integration. Integration is the defining feature of mixed methods but often poorly achieved or reported. If done well quantitative and quantitative analyses are integrated to become interdependent in reaching a common theoretical or research goal, thereby producing findings that are greater than the sum of the parts. $^{32}$

Practical and philosophical difficulties may have to be overcome to achieve integration. Different research methods are affiliated with different approaches to research which can operate with a different underlying philosophy and associated assumptions about the topic, the data collection, analysis and interpretation. Integration also requires a range of skills and resources which are not always 


\section{Advocating mixed-methods approaches}

available.

\section{Data analysis}

Once the component studies in a mixed-methods approach are completed, there is a challenge in how to pull them together to in a comprehensive way and address the overarching themes.

There are several practical issues relating to combining data, these may include: how to reduce and manage large volumes of data; how to facilitate the combining of them, for example which variables to focus on in the analysis. As mixed methods approach is relatively new researchers have had the freedom to experiment and influence combinations and techniques- and as a result, have become less rigid in their approach to analysis ${ }^{33}$. Recently, Fakis and colleagues used quantitative methods to analyse qualitative data interviews and concluded that complex qualitative information would benefit from further development of advanced statistical modeling methods suited to the data ${ }^{34}$.

Dixon-Woods and colleagues reviewed possible methods for synthesising qualitative and quantitative evidence and developed a framework of approaches ${ }^{35}$. It is now acceptable to use numeric techniques to analyse the vast amounts of qualitative data and narrative techniques to describe or explain quantitative data. New nomenclature has been devised: 'quantitise' refers to dealing with qualitative data in a quantitative manner and 'qualitise' refers to dealing with quantitative data in a qualitative manner ${ }^{35}$. Clearly, both qualitiative and quantative data individually need to be analysed in the most appropriate way and the research team must have the expertise to do this $^{36}$.

\section{Pulling it all together: Triangulation and Thematic Synthesis}

One way to address the bringing together of qualitative and quantitative date is to use an explanatory framework ${ }^{27}$. This follows a thematic synthesis process which entails taking the results of the component studies and generating new explanations and theory ${ }^{37-38}$. The accurate reporting of the use of mixed-methods and where and how integration is achieved is crucial in high quality research.

Stage 1: the base of the pyramid illustrates the foundation of the synthesis, the data collected and the analysis drawn from the component studies. This results in a large volume of information for analysis and write-up. These data can then be validated by categorising, content (thematic) analysis and concurrent triangulation ${ }^{39}$.

Stage 2: shows how the data are re-constructed using thematic analysis to re-categorise the data. This can be done by reading through the results and analysis and coding emerging themes, and going back to the component studies to test new themes in each.

Stage 3: triangulation can be used in various ways. First, the developed themes should be re-checked and retested, (this is called inter-investigator triangulation). Secondly, the aims and objectives of the overall study should be reviewed against the themes and analysed to establish how well objectives. From these theme tables the overall bulk of the data can be reduced further.

Stage 4: This leads to emergence of the overall explanatory and theoretical themes from which conclusions and recommendations are reached.

Figure 1: Explanatory Framework for Analysis.

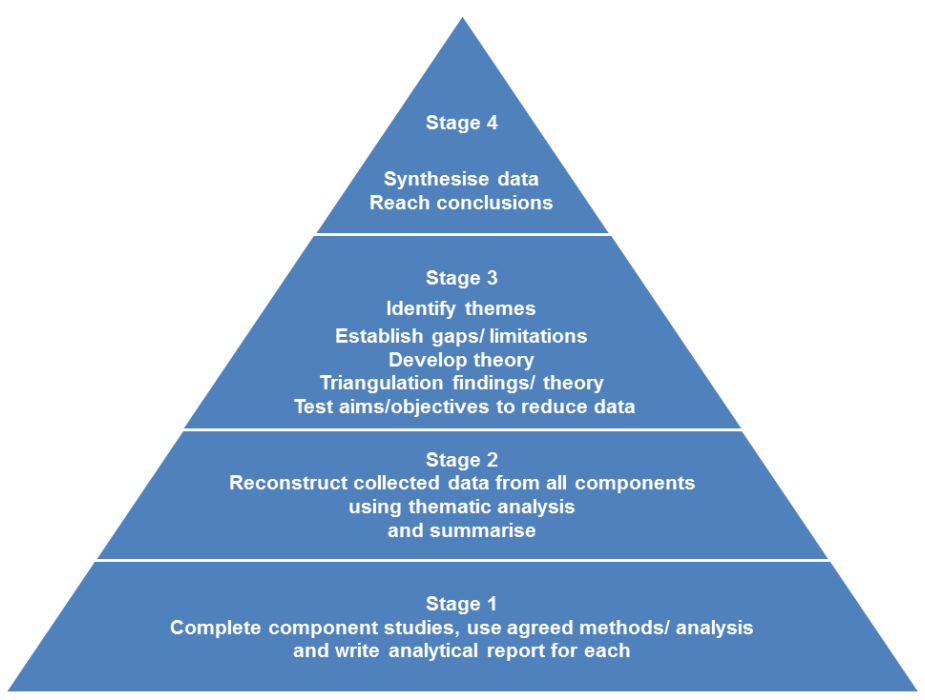

\section{Conclusion}

Traditionally, the aims of qualitative and quantitative research were sometimes regarded as being opposed, with the more purist proponents of each method claiming their approach to be better and a need to retain the different perspectives. Nonetheless, we have moved to a point where there is a broad recognition that both are necessary to explore the range of phenomena in healthcare and each method addresses another question or the same question differently. We, in line with a growing number of health researchers, argue that such antagonism or competition is negative and destructive and not conducive to good collaborative working. It also fails to recognise the unique contribution each methodological approach can make to our understanding of health in the wider social environment.

The challenges to conducting and maintaining high quality research using mixed methods are outlined in this paper. Nonetheless, the authors support the view that the sum of the parts when qualitative and quantitative methods are brought together is greater than either alone. The approach enables researchers with diverse expertise to work together in order to advance the evidence-base for practice. We hope that the guidance in this paper will encourage researchers to use the approach.

\section{Conflict of interest:}

None 


\section{References}

1. O'Cathain A, Murphy E, Nicholl J. Why, and how, mixed methods research is undertaken in health services research in England: a mixed methods study. BMC Health Serv Res 2007; 7: 85.

http://dx.doi.org/10.1186/1472-6963-7-85

PMid:17570838 PMCid:PMC1906856

2. McDowell I, MacLean L. Blending qualitative and quantitative study methods. Health Inform J; 1998;4:15-22. http://dx.doi.org/10.1177/146045829800400103

3. Duffy ME. Designing nursing research: the qualitativequantitative debate, J Adv Nurs 1987;10: 225-232. http://dx.doi.org/10.1111/j.1365-2648.1985.tb00516.x

4. Jick TD. Mixed Qualitative and quantitative methods: triangulation in action, Admin Sci Quart 1979; 24(4): 602611.

http://dx.doi.org/10.2307/2392366

5. Happ MB, DeVito Dabbs A, Tate J, Hricik A, Erlen J. Exemplars of Mixed Methods, Nurs Res 2006;55(2S): S43-49. http://dx.doi.org/10.1097/00006199-200603001-00008 PMid:16601634

6. Polit DF, Beck CT. Nursing Research, Principles and Methods, Philadelphia: Lippincott, Williams and Wilkin, 2007.

7. Tashakkori A, Teddlie C. (eds.) A Handbook of mixedmethods in social and behavioural research, Thousand Oaks, CA: Sage, 2003.

8. Testa M, Livingston J A, Tamsen, C. V-T. Advancing the study of violence against women using mixed-methods: integrating qualitative methods into a quantitative research program. Violence Against Women, 2011;17(2):236-250. PMid:21307032 PMCid:PMC3053530

9. Downe S, McCourt C. From being to becoming: reconstructing childbirth knowledges: In: Downe S. (Ed.). Normal birth, evidence and debate. Elsevier: Oxford, 2004. PMCid:PMC1721635

10. Freshwater D, Cahill J. Paradigms Lost and Paradigms Regained. J Mix Meth Res 2013; 7(1):3-5.

http://dx.doi.org/10.1177/1558689812471276

11. Howe KR. Against the quantitative-qualitative incompatibility thesis or dogmas diehard. Educ Res 1988;17(8): 10-16.

http://dx.doi.org/10.3102/0013189X017008010

12. Guba EG. What happened on the road to Damascus, In: Heshusius Z, Ballard K (eds) From positivism to interpretivism and beyond, New York, USA: Teachers College Press, 1996: 43-49.

13. Gage N.The Paradigm wars and their aftermath: $A$ historical sketch of research and teaching since 1989, Educ Res 1989;18(7): 4-10.

http://dx.doi.org/10.2307/1177163

http://dx.doi.org/10.3102/0013189X018007004

14. Cherryholmes CC. Notes on pragmatism and scientific realism, Educ Res; 1992; 21(6): 13-17.

http://dx.doi.org/10.3102/0013189X021006013
15. Kalof L, Dan A, Dietz T. Essentials of Social Research. Berkshire, UK: McGraw-Hill/Open University Press, 2008. 16. Mertens DM. What comes first? The paradigm or the approach. J Mix Meth Res 2012;6(4), 255-257 http://dx.doi.org/10.1177/1558689812461574

17. Feilzer YM. Doing Mixed Methods Research Pragmatically: Implications for the Rediscovery of Pragmatism as a Research Paradigm. J Mix Meth Res 2008;4(1):6-16.

http://dx.doi.org/10.1177/1558689809349691

18. Corner J. In search of more complete answers to research questions. Quantitative versus qualitative research methods: is there a way forward? J Adv Nurs 1991;16:718727

http://dx.doi.org/10.1111/j.1365-2648.1991.tb01730.x PMid:1869720

19. Bryman A. Multi-method research, In: Lewis-Beck MS, Bryman A, FuTng-Liao T, (eds) The Sage Encyclopaedia of Social Science Research Methods (Vol 2), 2008: 677-681. 20. Creswell JW, Fetters MD, Ivankova NV. Designing A Mixed Methods Study In Primary Care. Ann Fam Med. 2004;2(1):7-12.

http://dx.doi.org/10.1370/afm.104 PMid:15053277 PMCid:PMC1466635

21. Johnson RB, Onwuegbuzie A. Mixed Methods Research: A paradigm whose time has come. Educ Res 2004;33(7): 1426

http://dx.doi.org/10.3102/0013189x033007014

22. Mumtaz Z, Salway S. I never go anywhere: extricating the links between women's mobility and uptake of reproductive health services in Pakistan. Soc Sci Med 2005; 60: 1751-1765.

http://dx.doi.org/10.1016/j.socscimed.2004.08.019 PMid:15686807

23. Pitchforth E, van Teijlingen E, Graham W, Dixon-Woods $M$, Chowdhury M. Getting women to hospital is not enough: a qualitative study of access to emergency obstetric care in Bangladesh, Qual Saf Health Care 2006; 15: 214-219.

http://dx.doi.org/10.1136/qshc.2005.017285

PMid:16751473 PMCid:PMC2464855

24. Birjab J. Mixed Methods Studies: A Foundation for Primary Care Research, Ann Fam Med 2004; 2: 4-7. http://dx.doi.org/10.1370/afm.111

PMCid:PMC1466623

25. Greene JC, Caracelli VJ, Graham WF. Towards a conceptual framework for mixed methods evaluation designs. Educ Eval Pol Anal 1989; 11: 225-274.

http://dx.doi.org/10.3102/01623737011003255 http://dx.doi.org/10.2307/1163620

26. Greene JC, Caracelli VJ. Advances in mixed-methods evaluation: the challenges and benefits of integrating diverse paradigms. New directory for evaluation: No 74, San Francisco: Jossey Bass, 1997.

27. Miles MB, Huberman AM. Qualitative data analysis: an expanded sourcebook, Thousand Oaks CA: Sage, 1994.

28. Morse JM. Approaches to qualitative and quantitative 
methodological triangulation, Nurs Res 1991;40(2): 120-123. http://dx.doi.org/10.1097/00006199-199103000-00014 PMid:2003072

29. Johnson RB, Turner LA. Data collection strategies in mixed methods research, In: Tashakkori A, Teddlie C. (eds), A Handbook of Mixed Methods in Social and Behavioural Research, Thousand Oaks, CA: Sage, 2003: 279-319

30. Mays N, Pope C. Qualitative research in health care. London: BMJ Publishing Group, 1996.

31. Johnson B, Onwuegbuzie AJ, Turner LA. Towards a definition of mixed methods research. J Mix Meth Res 2007; 1(2):112-133.

http://dx.doi.org/10.1177/1558689806298224

32. Bazeley P. Computer assisted integration of mixed methods data sources and analyses. In: A. Tashakkori, C. Teddlie (eds.) A Handbook of Mixed Methods in Social and Behavioural Research (2nd ed), Thousand Oaks, CA: Sage, 2010: 431-467.

33. Sale J, Lohfeld L, Brazil K. Revisiting the quantitativequalitative debate: implications for mixed methods research. Qual Quant, 2002; 36(1): 43-53.

http://dx.doi.org/10.1023/A:1014301607592

34. Fakis A, Hilliam R, Stoneley H, Townend M. Quantitative Analysis of Qualitative Information from Interviews: A Systematic Literature Review. J Mix Meth Res 2014;8: 139161.

http://dx.doi.org/10.1177/1558689813495111

35. Dixon-Woods M, Agarwal S, Jones D, Young B, Sutton A. Synthesising qualitative and quantitative evidence: a review of possible methods, J Health Serv Res Pol 2005;10 (1): 4553.

http://dx.doi.org/10.1258/1355819052801804

PMid:15667704

36. Freshwater D. What Counts in Mixed Methods Research: Algorithmic Thinking or Inclusive Leadership? J Mix Meth Res 2014; 8(4): 327-329.

http://dx.doi.org/10.1177/1558689814553092

37. Pearson A. Balancing the evidence: incorporating the synthesis of qualitative data into systematic reviews. JBI Rep 2004; 2: 45-64.

http://dx.doi.org/10.1111/j.1479-6988.2004.00008.x

38. Sandelowski M, Barroso J, Voils $\mathrm{Cl}$. Using qualitative metasummary to synthesize qualitative and quantitative descriptive findings, Res Nurs Health. 2007; 30(1):99-111. http://dx.doi.org/10.1002/nur.20176

PMid:17243111 PMCid:PMC2329806

39. Cresswell JW. Research Design: qualitative, quantitative and mixed-methods approach. Thousand Oaks CA: Sage, 2003.

\section{Article Information}

\section{Article history}

Received

Received in revised form

Accepted $20^{\text {th }}$ December 2014

$25^{\text {th }}$ December 2014

$28^{\text {th }}$ December 2014 